\title{
UM PERCURSO PELA ANGÚSTIA NA OBRA DE FREUD
}

\author{
UM RECORRIDO POR LA ANGUSTIA EN LA OBRA DE FREUD
}

\author{
A ROUTE THROUGH THE ANGUISH IN FREUD'S WORK
}

\author{
Ana Carolina de Faria HUGUENIN ${ }^{1}$ \\ Lavínia Carvalho BRITO²
}

RESUMO: Este artigo apresenta um trajeto pelos principais textos de Sigmund Freud que têm como tema central a angústia. Desde o início de sua obra, este era um assunto abordado por Freud. Incialmente, a angústia aparecia relacionada diretamente às neuroses atuais, ponto de partida para uma primeira teoria da angústia, em que esta era considerada resultado de uma excitação sexual não descarregada. Com o passar dos anos, as abordagens em relação à angústia se modificam, culminando em uma segunda teoria da angústia, apresentada no famoso texto "Inibição, Sintoma e Angústia", de 1926. O objetivo deste trabalho, é expor em revisão bibliográfica, o percurso feito por Freud a respeito das teorias sobre a angústia e os principais conceitos que se articulam a ela.

PALAVRAS-CHAVE: Angústia. Sigmund Freud. Sexual.

RESUMEN: Este artículo presenta un recorrido por los principales textos de Sigmund Freud cuyo tema central es la angustia. Desde el inicio de su obra, este fue un tema abordado por Freud. Inicialmente, la angustia ha aparecido directamente relacionada con las neurosis actuales, punto de partida para una primera teoría de la angustia, en la que se consideraba el resultado de una excitación sexual no descargada. A lo largo de los años, los enfoques de la angustia han cambiado, culminando en una segunda teoría de la angustia, presentada en el famoso texto "Inhibición, síntoma y angustia", de 1926. El objetivo de este trabajo es exponer la revisión bibliográfica, el camino recorrido por Freud en cuanto a las teorías sobre la angustia y los principales conceptos que se vinculan a ella.

\section{PALABRAS CLAVE: Angustia. Sigmund Freud. Sexual.}

ABSTRACT: This paper presents a journey through the main texts of Sigmund Freud that have anguish as their central theme. Since the beginning of his work, this was a subject addressed by Freud. Initially, anguish appeared directly related to the current neuroses, starting point for a first theory of anguish, in which it was considered the result of an unloaded sexual excitement. As the years went by, the approaches to anguish changed,

\footnotetext{
${ }^{1}$ Centro Universitário de Barra Mansa (UBM), Barra Mansa - RJ - Brasil. Graduada no curso de Psicologia. ORCID: https://orcid.org/0000-0001-5952-2434.E-mail: adefariahuguenin@gmail.com

${ }^{2}$ Centro Universitário Geraldo Di Biasi (UGB), Rio de Janeiro - RJ - Brasil. Docente no curso de Psicologia UBM. Mestrado em Psicanálise (UERJ). ORCID: http://orcid.org/0000-0002-6639-4458. E-mail: laviniacbn@gmail.com
} 
culminating in a second theory of anguish, presented in the famous text "Inhibition, Symptom and Anguish" of 1926. The objective of this work is to present, in a bibliographical review, Freud's journey regarding the theories on anguish and the main concepts that are articulated to it.

KEYWORDS: Anguish. Sigmund Freud. Sexual.

\section{Introdução}

Este trabalho busca percorrer as principais elaborações acerca da angústia na obra freudiana. O tema angústia foi abordado por Freud, desde seus textos iniciais até o fim de seus escritos, a partir de duas teorias, as quais marcam dois momentos distintos de sua obra. A primeira teoria é essencialmente uma abordagem econômica, ou seja, refere-se a uma grande quantidade de energia sexual que invadiu o sujeito, como resultado de um coito insatisfatório. A angústia é então, neste momento, considerada como um intenso afeto de desprazer, vinculado estritamente à sexualidade. Em sua segunda teoria, Freud faz uma distinção entre dois tipos de angústia: sinal e automática. A primeira é a resposta do eu à ameaça de ocorrência de uma situação traumática, que é vista como perigo; as situações de perigo se modificam ao longa da vida, mas estão sempre relacionadas a uma situação de desamparo na medida em que envolve a separação ou perda de um objeto amado. A segunda diz respeito a uma resposta do eu à ameaça de uma ocorrência de uma situação traumática, em que o eu encontra-se em um estado de desamparo, desprovido de meios para lidar com uma excitação.

\section{A primeira teoria da angústia}

Freud, em 1894, enquanto se dedicava à escrita dos Estudos Sobre Histeria - em parceria com Breuer - estava também, conforme é possível ler nas cartas a Fliess completamente engajado na investigação dos problemas das neuroses: as "neuroses atuais" e as "psiconeuroses". Foi aqui que a teoria da defesa foi longamente discutida pela primeira vez. A importância do papel desempenhado pela sexualidade começa a emergir, bem como a ideia da divisão da mente em sistemas diferentes: consciente e inconsciente.

A principal diferença a respeito das neuroses atuais e as psiconeuroses pode ser estabelecida por meio de uma etiologia, enquanto as neuroses atuais eram tidas como uma consequência por uma interferência química, de um impedimento da satisfação sexual atual, as psiconeuroses eram vistas como consequência, de uma intermediação psíquica, de fixações e desvios da libido na infância. 
Freud (1894) afirma que em todos os casos analisados por ele na neurose obsessiva, era a vida sexual do sujeito que despertava um afeto aflitivo, algumas vezes da mesma natureza do ligado à sua obsessão. No entanto, por um lado, nem todos que sofrem possuem uma ideia tão clara sobre a origem do seu sofrimento, ao passo que os pacientes que estão conscientes da origem sexual de suas obsessões ou até mesmo de seus sofrimentos, por sua vez, as mantêm em segredo. Quando se queixam de suas obsessões, se espantam por estarem sujeitos ao afeto em questão, por sentirem angústia. Freud reitera ainda que para o médico experiente é ao contrário, o afeto aparece justificado e compreensível, o que ele acha notável é apenas que um afeto desse tipo esteja ligado a uma representação que não o merece (FREUD, 1894, p. 60).

Em alguns casos, a angústia liberada, cuja origem não deve ser lembrada pelo paciente, irá se apoderar das fobias primárias, comuns da espécie humana, relacionada a animais, tempestades, escuridão e assim por diante. Ao escolher a transposição do afeto como método de defesa, o eu leva muito menos vantagem do que escolher a conversão histérica da excitação psíquica.

A neurose de angústia vai compor o quadro das chamadas neuroses atuais, ao lado da neurastenia e da hipocondria, assim chamadas por estarem relacionadas à vida sexual atual do sujeito. Nesses casos, Freud (1894) supõe que ocorreria um acúmulo de excitação sem ligação com uma origem psíquica, ou seja, essas neuroses seriam fruto de problemas decorrentes da insatisfação sexual do sujeito. Tais neuroses apresentam duas formas de emergência: ataques de angústia e estado crônico, mais brando e com aparecimento flutuante. A descrição freudiana dessa modalidade neurótica se assemelha bastante aos atualmente chamados transtornos de ansiedade, os quais incluem os ataques de pânico e a ansiedade generalizada.

Do ponto de vista clínico, a neurose de angústia descrita por Freud possui sintomas relacionados de modo muito mais estreito entre si, ao contrário do que ocorre na neurastenia genuína, em que a etiologia e mecanismos são diferentes. Todos os sintomas da neurose de angústia podem ser agrupados em torno de um eixo principal, que é a própria angústia. Entre os sintomas mais gerais aparecem: irritabilidade geral, expectativa angustiada, ataques de angústia e acordar em pânico à noite.

É interessante observar que, em alguns casos de neurose de angústia, não é encontrado nenhuma etiologia, raramente há uma dificuldade em se estabelecerem como fator hereditário. Freud afirma: 
quando há fundamentos para se considerar a neurose como adquirida, uma cuidadosa investigação orientada nesse sentido revela que um conjunto de perturbações e influências da vida sexual são os fatores etiológicos atuantes (FREUD, 1895, p. 98).

Segundo Freud (1895), é recomendado considerarmos a incidência da neurose de angústia separadamente, entre homens e mulheres. Sendo assim, nas mulheres pode ocorrer: angústia virginal ou angústia nas adolescentes; angústia das recém-casadas; angústia de mulheres que sofrem de ejaculação precoce; angústia em viúvas ou abstinentes; angústia no climatério. Nos homens, seus grupos possuem analogias nas mulheres: angústia em homens voluntariamente abstinente; angústia em estado de excitação não consumado; angústia no coito interrompido; angústia em homens senescentes.

Inicialmente, Freud tinha uma suspeita de que se tratava de um acúmulo de excitação, e que não seria possível que obtivesse sintomas clínicos de origem psíquica clássicos da neurose. A histeria ou uma neurose traumática podem ser adquiridas, mas não a neurose de angústia. Enquanto a neurastenia surge sempre que a descarga adequada é substituída por uma menos adequada, a neurose de angústia por sua vez, é produto de todos os fatores que impedem a excitação sexual somática de ser psiquicamente elaborada.

Segundo Freud:

A psique é invadida pelo afeto de angústia quando se sente incapaz de lidar, por meio de uma reação apropriada, com uma tarefa (um perigo) vinda de fora; e fica presa dentro de uma neurose de angústia quando se percebe incapaz de equilibrar a excitação (sexual) vinda de dentro - em outras palavras, ela se comporta como se tivesse projetando tal excitação para fora [...] O afeto é um estado que passa rapidamente, enquanto a neurose é um estado crônico, porque, enquanto a excitação exógena age num único impacto, a excitação endógena atua como uma força constante (FREUD, 1984, p. 109).

Em 1916, Freud dedica toda uma conferência à Angústia, pois, segundo ele, questões relativas ao tema não ficaram esclarecidas em sua última conferência a respeito do estado neurótico, já que não havia trabalhado a angústia propriamente dita. É um sintoma que todos os neuróticos se queixam como sendo o pior sofrimento, o que pode acabar resultando em atitudes consideradas loucas! Com isso, Freud vem a pensar que os neuróticos sentem a angústia de maneira muito mais intensa do que as outras pessoas.

Segundo Freud (1916), podemos experimentar dois tipos de angústia: a realística e a neurótica. Ele define a angústia realística como algo mais racional, um estado de autopreservação, um reflexo de fuga a um perigo externo. Está relacionada ao conhecimento da pessoa, que a possibilita reconhecer precocemente o perigo. 
Se pararmos para analisar, a angústia realística, de certa maneira, se torna vantajosa, pelo fato de que ela consegue nos fornecer um "alerta" para o perigo que pode estar a nossa frente. Consegue, em meio ao caos, achar a melhor saída para aquela situação. Porém, quando essa angústia é exacerbada, ela se torna o perigo, pois no momento de fuga, ela pode paralisar o sujeito. Com isso, Freud conclui que a geração de angústia nunca é apropriada! Por não sabermos qual será a reação durante determinado momento.

O surgimento da angústia pode ser equiparado a um afeto. Mas o que seria um afeto? Ao se questionar, Freud (1916) diz que a essência de um afeto vai muito além de inervações ou descargas motoras. Sua hipótese é de que um estado afetivo seria formado da mesma maneira que um ataque histérico, sendo assim, este ataque histérico pode ser igualado a um afeto individual, recentemente formado e um afeto normal, a expressão de uma histeria geral que se tornou herança.

Dessa forma, o afeto da angústia é a vivência original do ato do nascimento que está sendo repetida, pois é neste que há sensações desprazerosas, impulsos de descarga e sensações corporais. $\mathrm{O}$ ato do nascimento se tornou um protótipo de um "perigo mortal", que é repetido por nós como o estado de angústia.

Se pararmos, agora, para pensar a angústia neurótica, como ela se manifesta, quais novas formas se apresentam nela? Ela surge através de uma apreensão, uma angústia flutuante. Está pronta para se ligar a uma ideia que seja apropriada para esse fim. Freud chamou este tipo de angústia de expectante.

As pessoas atormentadas pela angústia expectante sempre interpretam os eventos, mesmo aqueles casuais, como algum presságio do mal e exploram as incertezas em um mau sentido. São características facilmente encontradas em pessoas que se dizem apenas super ansiosas ou pessimistas, mas Freud inclui nos casos de 'neurose de angústia'.

A segunda forma de angústia, apontada por Freud (1916), em oposição à mencionada anteriormente, está vinculada a determinados objetos e situações. Trata-se da angústia das fobias, dividida em três grupos. O primeiro grupo está relacionado a objetos; o segundo grupo, a situações; e o terceiro grupo, aos animais. A angústia presente nas fobias dos neuróticos é avassaladora, o que parece estranho não é o conteúdo, mas sim a intensidade em que se apresenta. Além disso, todas essas fobias podem ser classificadas como histeria de angústia, ou seja, um distúrbio relacionado com a histeria de conversão.

A terceira forma de angústia, chamada angústia neurótica não possui qualquer relação com um perigo ameaçador, foge completamente à percepção construída até agora. Freud 
utiliza como exemplo, o caso da histeria que, em alguma situação de excitação se espera alguma manifestação de afeto, mas jamais de angústia. Assim, Freud diz:

Aqui não há nenhum sinal de qualquer perigo ou de qualquer causa que pudesse ser enxergada como perigo. E logo verificamos, a partir desses ataques espontâneos que o complexo que descrevemos como um estado de ansiedade é passível de fracionamento. $\mathrm{O}$ ataque total pode ser representado por um único sintoma, intensamente desenvolvido[...] Então, essas condições que descrevemos como 'equivalentes da angústia' devem ser igualadas à angústia para todos os fins clínicos e etiológicos (FREUD, 1916, p. 467).

Contudo, mesmo surgindo questões de como é possível compreender a angústia neurótica, Freud ainda se inclina na expectativa de que onde há angústia, deve haver algo para se temer.

A angústia expectante, depende justamente de alguns acontecimentos da vida sexual ou de empregos da libido. Conforme já descrito anteriormente, a angústia se relaciona a primeira teoria da libido.

Nas psiconeuroses, a angústia quase sempre aparece como uma forma de sintoma, mas também é possível surgir a angústia desvinculada, que se manifesta como uma condição crônica. Após o recalque há o deslocamento da ideia e a transformação do afeto em angústia. Já aqueles que sofrem de atos obsessivos, os ditos rituais parecem ser isentos de angústia. Porém, quando impedidos de realizá-los, ou quando tentam não mais realizá-los, são submetidos a uma terrível angústia para realizar a compulsão. Assim, Freud diz que angústia sempre esteve presente, porém, estava coberta pelo ato obsessivo. E isso também acontece na histeria e o resultado do recalque é a angústia.

Após essas observações sobre a psiconeurose, Freud chega à conclusão a uma conexão que estava procurando:

[...] como nosso ponto de partida a oposição que tantas vezes afirmamos existir, entre o ego e a libido. Conforme sabemos a geração de angústia é a reação do ego ao perigo e o sinal para empreender a fuga. Assim sendo, parece plausível supor que, na angústia neurótica, o ego faz uma tentativa semelhante de fuga para exigência feita por sua libido, que o ego trata este perigo interno como se fora um perigo externo. Portanto, isto corresponde à nossa expectativa de que, onde se manifesta angústia, aí existe algo que se teme. Assim como a tentativa de fuga de um perigo externo é substituída pela adoção de uma atitude firme e de medidas apropriadas de defesa, também a geração de angústia neurótica dá lugar à formação de sintomas, e isto resulta em que a angústia seja vinculada (FREUD, 1916, p. 471).

A angústia é uma fuga do eu para longe de sua própria libido, porém isso é algo contraditório de se dizer, pois a libido não pode ser colocada em contraste com a própria 
pessoa, como algo externo. Com isso, surge mais uma questão a respeito da topografia da angústia e para pensar em resolver essa questão, Freud volta à gênese da angústia em crianças e na origem da angústia neurótica vinculada às fobias.

Uma criança, frequentemente, possui um estado de apreensão e é difícil distinguir se trata-se de uma angústia realística ou neurótica. No início da infância, a criança teme pessoas estranhas, porém ela não teme esses estranhos por associar a más intenções. Para Freud (1916), a criança tem medo de estranhos porque está habituada a figuras familiares - sua mãe. Seu anseio pela mãe é que se transforma em angústia - a libido da criança não consegue ficar suspensa e se descarrega em forma de angústia.

Em casos de fobia, as primeiras são relativas a situações de escuridão ou solidão. Aqui também ambas estão relacionadas à criança sentir a ausência de alguma pessoa amada que cuida dela - sua mãe -. Em todos os casos que posteriormente podem se tornar um fator para fobia, as crianças não demonstram angústia e quanto maior sua ignorância, menor sua angústia.

Segundo Freud:

a angústia infantil tem escassa relação com a angústia realística, mas por outro lado, relaciona-se estreitamente com a angústia neurótica dos adultos. Assim como esta, deriva-se da libido não utilizada e substitui o objeto de amor ausente por um objeto externo, ou por uma situação (FREUD, 1916, p. 476).

Assim como na angústia das crianças, na fobia, a libido que não foi utilizada é transformada em angústia que aparenta ser realística, um perigo externo insignificante é introduzido para representar as exigências da libido. Toda "histeria de angústia", remonta a uma angústia infantil e é continuação desta, mesmo que tenha um conteúdo diferente e receba também um outro nome.

Assim, na primeira teoria da angústia, a transformação em angústia é o destino imediato da libido quando há recalque. Mas este não é o único e nem o definitivo destino desta libido, pois, nas neuroses, existem processos que buscam vincular a angústia. Nas fobias, pode ser dividido em duas fase. A primeira fase, o recalque e à transferência de libido em angústia, a qual é vinculada a um perigo externo. A segunda fase é referente a tomar precauções e garantias, mediante as quais se possa evitar todo contato com esse perigo, que é tratado como uma coisa externa que é. 


\section{Articulações entre angústia e o Unheimlich}

No percurso para compreender melhor a angústia em Freud, outro importante texto é “O Estranho” de 1919. Não podemos dizer que é um texto cujo tema principal é a angústia, mas é nele que Freud faz descobertas importantes sobre o tema e articula o "estranho" com a angústia.

Escrito paralelamente a "Mais além do princípio de prazer" de 1920, este texto freudiano discorre sobre o tema do "estranho", geralmente associado a algo assustador, que provoca medo e horror. Inicialmente Freud propõe analisar as significações da palavra Estranho - Unheimlich no original em alemão, que significa não domesticado, não familiar, estranho - e sua palavra oposta Heimlich - domesticado, do lar, nativo -. A grande descoberta de Freud é que entre as diferentes acepções da palavra Heimlich, desenvolveu-se um significado em que ela é idêntica ao seu oposto, Unheimilich.

Shelling (apud FREUD, [1919] 1990, p. 281) define a palavra Unheimilich como "tudo aquilo que deveria ter permanecido secreto e oculto, mas veio à luz". Freud faz uma associação com o inconsciente, ou seja, tudo aquilo que estava fora da consciência e que por meio dos sonhos, chistes, atos falhos, veio à tona.

Para exemplificar melhor assunto, Freud recorre à história do Homem de Areia personagem assustador que vem arrancar os olhos das crianças que não querem dormir. Esse medo da criança de ter arrancados os olhos, Freud diz que muitas vezes trata-se de um substituto do medo de ser castrado, o que foi possível perceber através dos sonhos, das fantasias e dos mitos. No conto, é possível destacar personagens que são considerados idênticos, ponto em que Freud fala sobre o fenômeno do duplo, outra fonte do sentimento de estranheza. O fenômeno do "duplo" abordado por Otto Rank (apud FREUD, [1919] 1914) é quando o sujeito se identifica com outra pessoa, de uma forma tão intensa, que se coloca em dúvida quem é o seu eu, há um intercâmbio do eu. Segundo ele, o "duplo" tem ligações com reflexos em espelhos, com sombras, com os espíritos.

Segundo Freud:

[...] temos que admitir, nada disso nos ajuda a compreender a sensação extraordinariamente intensa de algo estranho que permeia a concepção; e o nosso conhecimento dos processos mentais patológicos permite-nos acrescentar que nada, nesse material mais superficial, podia ser levado em conta na ânsia de defesa que levou o ego a projetar para fora aquele material, como algo estranho a si mesmo (FREUD, 1919, p. 295). 
Outra ideia abordada neste texto que se articula à angústia é a "compulsão à repetição" Para melhor explicá-la, Freud recorre ao seguinte exemplo: em uma tarde de verão caminhava pelas ruas de uma cidade da província da Itália e parou em uma rua deserta; logo, se apressou e continuou caminhando, porém, quando se deu conta, estava novamente nesta mesma rua, e completou que naquele momento sentiu uma sensação de estranheza, e chamou isso de retorno involuntário. Se pararmos para pensar, essa repetição involuntária muitos chamariam de sorte, quando avistamos o mesmo número diversas vezes, por exemplo e sempre tentamos designar um significado a respeito dessa ocorrência (FREUD, 1919).

A partir desse exemplo dado por Freud, identificamos a concepção de compulsão à repetição:

[...] é possível reconhecer na mente inconsciente, a predominância de uma "compulsão a repetição", procedente dos impulsos pulsionais e provavelmente inerente à própria natureza das pulsões - uma compulsão poderosa o bastante para prevalecer sobre o princípio de prazer, emprestando a determinados aspectos da mente o seu caráter demoníaco, e ainda muito claramente expressa nos impulsos das crianças pequenas; uma compulsão que é responsável, também, por uma parte do rumo tomado pelas análises de pacientes neuróticos. Todas essas considerações preparam-nos para a descoberta de que o quer que nos lembre esta íntima 'compulsão à repetição" é percebido como estranho (FREUD, 1919, p. 297).

A teoria psicanalítica sustenta a ideia de que todo afeto pertence a um impulso emocional e, quando recalcado, este se transforma em angústia. Logo, dentre todos os exemplos de elementos assustadores, deve haver alguma categoria em que o objeto que assusta pode ser algo recalcado que retornou, ou seja, constitui um retorno do recalcado. E esta categoria de coisas assustadoras, seria então o estranho. Este que não é nada novo ou alheio, porém algo familiar que somente se alienou por este processo de recalcamento.

Assim, Freud (1919) afirma: uma experiência estranha ocorre quando os complexos infantis que haviam sido recalcados revivem uma vez mais por meio de alguma impressão, ou quando as crenças primitivas que foram superada parecem outra vez. Com isso, são elementos que participam da formação da angústia infantil, elementos que a maioria dos seres humanos jamais se libertou inteiramente.

\section{Segunda teoria da angústia}

Em 1926, no texto "Inibição Sintoma e Angústia", Freud modifica sua teoria de que a angústia seria originada pela libido. Considera a angústia, então, como uma reação a uma 
situação de perigo ou traumática. Também neste texto é abandonada a dicotomia entre angústia realística e angústia neurótica. Em ambas as situações, trata-se do medo de uma ameaça: no primeiro caso, uma ameaça vinda de fora e; no segundo, uma ameaça interna, ou seja, a própria excitação sexual. Além disso, Freud afirma que apesar das situações de perigo serem diversas, o medo da perda do objeto amado é um ponto em comum.

Freud (1926) aponta que o nascimento seria o momento inaugural da angústia, protótipo de todas as situações posteriores de perigo. $\mathrm{O}$ nascimento constituiria um primeiro trauma que ao projetar o sujeito numa vivência de desamparo, provocaria para o eu um excesso de estímulo impossível de ser descarregado.

Ainda de acordo com Freud, há uma relação entre inibição e angústia, visto que as primeiras inibições podem surgir como uma tentativa de evitar a angústia. E de onde vem essas inibições? Para ele, são diferentes origens: em decorrência de uma tentativa do eu evitar um conflito com o isso, com o supereu ou podem ocorrer em função de um empobrecimento da quantidade de energia.

Um sintoma, ao contrário de uma inibição, é um sinal de algo patológico e que não ocorre dentro do eu, mas atua sobre este. O sintoma é acarretado pelo recalque, sendo um sinal e um substituto de uma satisfação pulsional. Assim, Freud destaca que o processo de recalque ocorre no ego e que este é a sede da angústia. A angústia é a condição necessária para o surgimento do sintoma, pois é ela que desperta o mecanismo de prazer-desprazer, que paralisa os processos do isso.

Freud retoma os famosos casos do Pequeno Hans e do Homem dos Lobos, analisados por ele anteriormente. $\mathrm{O}$ primeiro trata de uma fobia de cavalos em um menino de cinco anos e o segundo de um paciente adulto cuja neurose começou na infância, apresentando diversos sintomas, inclusive uma fobia. Em ambos os casos, observa-se a presença de sentimentos ambivalentes em relação à figura paterna. Ele afirma que, nestes pacientes, o impulso hostil contra o pai sofreu recalque e o sintoma foi formado pelo deslocamento da figura do pai para de um animal: no caso de Hans o cavalo; e no caso do Homem dos Lobos, o lobo.

A força motriz do recalque nestes casos clínicos teria sido o temor da castração, confirmando que a origem do recalque estaria na angústia, no medo de um perigo (castração).

Foi a angústia que produziu o recalque e não, como eu anteriormente acreditava, o recalque que produziu a angústia [...]. É sempre a atitude de angústia do eu que é a coisa primária e que põe em movimento a angústia. A angústia jamais surge da libido recalcada" (FREUD, 1926, p. 111). 
Com isso, Freud chega à conclusão de que a angústia não se resume ao desprazer. Embora haja essa característica, ela não é a única. Trata-se da ameaça de um perigo desconhecido, um desamparo psíquico, relativo a cada fase da vida:

\begin{abstract}
Assim o perigo de desamparo psíquico é apropriado ao perigo de vida quando o eu do indivíduo é imaturo; o perigo da perda de objeto, até a primeira infância, quando ele ainda se acha na dependência de outros; o perigo de castração até a fase fálica; e o medo do seu supereu, até o período de latência. Não obstante, todas essas situações de perigo e determinantes de angústia podem resistir lado a lado e fazer com que o eu a elas reaja com angústia num período ulterior ao apropriado; ou além disto, várias delas podem entrar em ação ao mesmo tempo (FREUD, 1926, p. 140).
\end{abstract}

Em 1933, Freud reafirma a teoria apresentada em "Inibição Sintoma e Angústia" (1926), porém, agora, o faz sob a forma de conferência, intitulada "Angústia e vida pulsional". O autor destaca como ponto principal o fato de que a angústia não é o produto do recalque, mas sim o que causa o recalque.

Assim:

[...] Parece que a angústia, na medida em que constitui um estado afetivo, é a reprodução de um evento antigo que representou uma ameaça de perigo; a angústia serve ao propósito de autopreservação e é sinal de um novo perigo; surge da libido que se tornou de algum modo não utilizável e também surge durante o processo de recalque; é substituída pela formação de um sintoma, é, digamos assim, psiquicamente vinculada - tem-se a impressão de que aqui está faltando algo que juntaria todas essas peças em um todo (FREUD, 1933, p. 107).

Além disso, após a segunda tópica, em que Freud divide o aparelho psíquico em $e u$, isso e supereu, ele apresenta uma posição nova no que diz respeito à angústia. Os principais tipos de angústia se relacionariam a alguma pressão que o eu - sede da angústia - sofre em função das relações de dependência que ele estabelece. Assim, a angústia realística ocorre devido a relação do eu com o mundo externo; a angústia neurótica, como resultado das pressões do isso e a angústia moral como exigência do supereu.

Finalmente, a partir de toda sua elaboração acerca da angústia e das maneiras como ela se presentifica, Freud sintetiza seus achados em dois tipos de expressão da angústia. Assim, podemos considerar a existência da angústia sinal, a qual possui uma função de proteção, uma vez que prepara o eu antecipando o traumático. A angústia sinal está a serviço do princípio de prazer e, portanto, da pulsão de vida, ou seja, sinaliza e protege o psiquismo. O outro tipo é chamado angústia automática e configura o reencontro com o traumático que, em psicanálise, trata-se sempre de uma quantidade de excitação excessiva que o aparelho psíquico não pode 
processar (FREUD, 1933). A angústia automática não permite que o eu se prepare e se defenda, de forma que está na ordem do irrepresentável e, por isso mesmo, articula-se ao que Freud nomeou como pulsão de morte.

\section{Conclusão}

Após percorrer o trajeto feito por Freud a respeito da angústia, percebe-se que este assunto constitui um dos pilares da teoria psicanalítica. É como uma árvore com suas ramificações, ou seja, a angústia se articula também com outros importantes conceitos para a psicanálise, tais como a libido, a inibição, o recalque, o sintoma, entre outros.

A partir deste trabalho, constatamos que Freud construiu duas teorias bem demarcadas acerca da angústia, as quais se relacionam a dois momentos distintos de sua obra e de suas elaborações. Em um primeiro momento, a angústia é resultado de uma excitação sexual não descarregada, ou seja, aqui a angústia se apresenta atrelada à sexualidade. No entanto, como lembra Leite (2011), os avanços a partir da experiência clínica de Freud, a descoberta do complexo de Édipo e do temor da castração, bem como o tema da culpa e a elaboração da segunda tópica levam a uma nova perspectiva em relação à angústia. Neste segundo momento, a angústia é definida como um estado afetivo e relaciona-se `a ideia de desamparo psíquico, seja automaticamente - na vivência traumática - ou como um sinal, o qual permite ao eu um preparo que tem a função de evitar reviver a situação traumática.

\section{REFERÊNCIAS}

FREUD, S. As neuropsicoses de defesa. In: Edição Standard Brasileira das Obras Psicológicas Completas de Sigmund Freud. v. III. Rio de Janeiro: Imago Editora, 1969.

FREUD, S. A ansiedade. In: Edição Standard Brasileira das Obras Psicológicas Completas de Sigmund Freud. v. XVI. Rio de Janeiro: Imago Editora, 1969.

FREUD, S. O estranho. In: Edição Standard Brasileira das Obras Psicológicas Completas de Sigmund Freud. v. XVII. Rio de Janeiro: Imago Editora, 1969.

FREUD, S. Inibições, sintoma e angústia. In: Edição Standard Brasileira das Obras Psicológicas Completas de Sigmund Freud. v. XVII. São Paulo: Companhia das Letras, 2014.

FREUD, S. A ansiedade e vida instintual. In: Edição Standard Brasileira das Obras Psicológicas Completas de Sigmund Freud. v. XXII. Rio de Janeiro: Imago Editora, 1969. 
JORGE, M. A. C. Fundamentos da psicanálise de Freud e Lacan: a prática analítica. v. 3. Rio de Janeiro: Zahar, 2017.

LEITE, S. Angústia. Rio de Janeiro: Zahar, 2011.

\section{Como referenciar este artigo}

HUGUENIN, A. C. de F.; BRITO, L. C. Um percurso pela angústia na obra de Freud. Doxa: Rev. Bras. Psico. e Educ., Araraquara, v. 22, n. esp. 1, p. 271-283, out., 2020. e-ISSN: 25948385. DOI: https://doi.org/10.30715/doxa.v22iesp.1.14133

Submetido em: 20/04/2020

Revisões requeridas: $15 / 06 / 2020$

Aprovado em: 20/08/2020

Publicado em: 30/09/2020 